\title{
Pop(-up)ular Culture at the Seaside: The British Pleasure Pier as Screening Space
}

\section{Introduction}

This chapter explores a set of enquiries situated at the intersections of cinema-as-event, community cinema and the current cultural development of 're-purposing' seaside piers as community spaces. Drawing on empirical explorations of pop-up cinema on seaside piers, it seeks to historicise the relationship between cinematic viewing practices and Victorian seaside piers, as well as to investigate the role of outdoor cinema in the changing landscape of contemporary seaside resort entertainment. The case studies presented here also illustrate the potential of outdoor deck top cinema as an immersive cinema experience when the seascape and the sounds of the natural surroundings blend with the film's mise-en-scène.

In their earliest incarnation piers were practical structures, serving as landing stages for goods and holidaymakers arriving to seaside resorts via boat. While this functionality remained important throughout the nineteenth century, at least until an expanded rail network offered an alterative means of accessing coastal locations, their pleasurable aspects soon became apparent. This led them to evolve in many different directions over the years, with well-documented fluctuating fortunes (see, for example, Fischer and Walton 1987; Gray 2006; Shaw and Williams eds 1997). Today only fifty nine of the original hundred or so British seaside piers remain, and many of those are under threat. Despite this downturn piers remain important to the coastal communities in which they are situated - in terms of serving as a landmark that gives the town a sense of identity (no two piers are the same), in terms of the local economy and in terms of community heritage - aspects which, we argue, are made manifest in their use as twenty-first century screening spaces. 
Since the post-war decline in British seaside resort culture, it has been a battle for most pleasure piers to survive. Exposed to sea and weather, the Victorian constructions are expensive to maintain and due to the social stratification of cultural consumption their offerings of popular entertainment have typically not been considered worthy of investment. Anya Chapman identifies this as an area where more academic work is needed and notes that 'research into the sustainability of these iconic structures is a matter of urgency' (2015: n.p.). Piers that have fallen into permanent disrepair include Birnbeck Pier in Weston-super-Mare, South West England, while those that have survived, like the neighbouring Grand Pier, often adopt warehouse-like structures to house amusement arcades in a move to make their business less weather dependant. In recent years, however, several seaside resorts have sought a community solution to owning and managing the local pier, for example, Clevedon Pier, also on England's southwest coast, and Hastings Pier in South East England. These two community piers are the focus of this chapter.

Piers are more than just Victorian structures of metal and wood and, indeed, more than treasured architectural landmarks - they are lived experiences with a rich popular culture history fuelled by a liminality whereby they are positioned at a slant in relation to on shore life. In an increasing number of cases it can be argued that seaside piers are potentially reinventing themselves as twenty-first century community spaces, as explored in the Connected Communities themed 'The People’s Pier’ research project funded by the Arts and Humanities Research Council (2015-16). ${ }^{1}$ This project is a collaboration between four UK universities $^{2}$ and two community partners, the Hastings Pier Charity and the Clevedon Pier and Heritage Trust. Together we have explored ways of utilising the popular cultural heritage of the seaside piers to engage with groups in the local communities that the pier organisations

\footnotetext{
1 AHRC project reference AH/M009300/1.

${ }^{2}$ These are: University of Brighton, University of Bristol, University of Edinburgh and University of Kent.
} 
have identified as under-represented in their target audience, or otherwise marginalised, thus further empowering the organisations in the work they do for the benefit of the community. This has included piloting immersive sound and visual activities on the piers, such as a lively audio tour inspired by the silent disco format as well as the film screenings that are the focus of this chapter. These activities were designed with the aim of potentially changing perceptions among young people by giving them new reference points to the pier, replacing negative associations of dereliction and disinterest. The respective piers' popular cultural heritage, as music and dance venues, but also in terms of the end-of-pier entertainment genre and protofilmic devices has been at the heart of these initiatives and the project has drawn on materials from both community archives and oral history research conducted as part of the project.

Investigating the emergence of pop-up cinema in this environment, the chapter gives particular attention to the potential of this contemporary mode of film exhibition for the purpose of community cinema and the rejuvenation of piers. We use qualitative data gathered through an audience survey and interviews conducted in conjunction with an outdoor event cinema pilot project on Clevedon Pier as well as through participant observation at the first deck top cinema on Hastings Pier. Unlike the more traditional sites for outdoor summer screenings in the UK, such as the grounds of English castles or the country’s numerous parks, piers as temporary film exhibition sites are especially significant in their offer of repurposing and, therefore, rejuvenating spaces that for several decades have been threatened with permanent closure or disrepair. This kind of culture-led regeneration is evident elsewhere (see, for example, Lashua 2013) but it is especially welcome at the seaside resort which was once replete with spectacle and performance-based pleasures and a 'happy hunting ground for cinema promoters' (Walton 2000: 97). 


\section{From coastal scenes to coastal screens: researching the seaside spaces of cinema}

Costal locations have piqued the interest of Film Studies scholars in recent years. Steven Allen's examination of a 'converse representation of the seaside' (2009: 54) in British film; Brady Hammond and Sean Redmond's shoreline-themed edition of the journal Continuum that considers 'those directors and films for which the relationship between sea and land at the shoreline and beach is of particular narrative, aesthetic and ideological significance’ (2013: 601); and Fiona Handyside’s sustained analysis of the beach in French cinema (2014) are a welcome addition to place-based studies of film, especially in further shifting attention from the once almost obsessive analytical focus on the city-cinema relationship.

The work conducted thus far, however, is frequently attached to the representational possibilities that the coast affords filmmakers. The sensorial properties of beaches, ports, cliff tops and coastal resorts - from the striking vistas afforded by the sharp lines of the horizon to the cacophonous soundscapes produced by seaside amusements - indeed offer dynamic spaces in which to display and develop narrative, thematic and aesthetic interests. As Murray Pomerance comments in his analysis of the young body on the beach, sandy shores on screen often become 'a setting for notable drama either emphatic, or romantic or apotheotic' (2013: 619) or as Lara Feigel notes in her work on 1930s British films, the popular seaside resort in the early twentieth century was an artistically potent setting: 'The seaside filmmaker could dizzy his audience as it bounced with the camera along the rollercoaster’ (2009: 15). Though, undeniably, there is still more work to be done regarding the on-screen embodiment of coastal locations, there is also a concurrent need for further work that explores how these sites serve the industrial practices of film including networks of exhibition and reception. The aims of this chapter thus intersect with those of the HoMER network (homernetwork.org) and the recently completed ‘Early Cinema in Scotland, 1896-1927’ research project 
(earlycinema.gla.ac.uk), especially María Antonia Vélez-Serna’s work on ‘mapping [a] landscape of non-metropolitan film exhibition’ (2016: 286).

In her analysis of the 'mythical Riviera' Handyside offers the Cannes Film Festival as one example of how seaside locations serve cinematic systems of display. Her study shows how the festival, through its signifier of a sun-drenched beachscape and its connection to the stardom of (an oft bikini-clad) Brigit Bardot, had a particularly significant impact on the cultural economy of 1950s France (2015: 49-62). The UK may not have similarly glamorous resorts in which to host an international film festival but seaside towns, such as Blackpool on England's northwest coast and Brighton in the southeast, prove to be important locations when tracing developments in the country's film-going culture. Sue Arthur, for example, identifies Blackpool as 'an accelerator for national trends in entertainment' in the first half of the twentieth century (2009: 37), noting how the town's early conversion of cinemas to sound (from 1929 onwards) responded to growing demands from the pleasure-seeking British public.

Technological advancements in today's world open up further possibilities for the UK's seaside locations, especially those seeking to become (re-)established as exciting centres of popular culture. Lightweight (often inflatable) screens, powerful projectors, portable sound systems, and silent generators that make power sources redundant allow coastal locations to not only use their traditional indoor spaces for film screenings - whether purpose-built cinemas or multi-purpose pavilions - but, also, make use of the outdoor spaces - from shingle beaches to deck top piers - that make these coastal locations so appealing in the first place. With the 'growing trend toward the creation of a cinema that escapes the boundaries of the auditorium' (Atkinson and Kennedy 2016a: 139) it thus seems an opportune moment to consider how exterior sites of exhibition at the seaside might work in 
practice, and how such screening events might feed into current developments in UK cinemagoing as well as resonate with older traditions of seaside entertainment.

Celebrations for the fortieth anniversary of Steven Spielberg's Jaws (1975) in 2015 fuelled this line of inquiry. Intersecting with the increased demand for experiential cinema, they prompted various screening events that relate to what Sarah Atkinson and Helen W. Kennedy term 'augmented cinema' (2016a: 141). Typically these events focused on situating the audience in locations relevant to the film's story of a great white shark attacking beachgoers in the fictional New England resort town 'Amity Island'. The highest profile screenings for Jaws in summer 2015 were organised by the Alamo Drafthouse Cinema based in Austin, Texas. Known for its attention to detail in film presentation and a decade old 'Rolling Roadshow' that has presented outdoor film screenings and 'unique movie adventures’ (drafthouse.com/series/rollingroadshow), the Alamo Drafthouse hosted its anniversary screenings of Jaws on a man-made lake, surrounded by sandy beaches, with audiences invited to swim or float on rubber tubes as they watched the drama unfold. The evocative staging of the screenings prompted CNN's Karla Cripps to ask 'Could there possibly be any scarier way to watch “Jaws”?’ (2015: n.p.) while, writing for British newspaper The Independent, Christopher Hooten stated, 'This is surely the best way to watch Jaws’ (2015: n.p.). By comparison experiential cinema events for the fortieth anniversary of Jaws in the UK were more muted affairs. Following Atkinson and Kennedy’s typography, some offered creative interventions more akin to 'enhanced cinema' (2016a: 141) whereby an outdoor setting unrelated to the film text was used to screen the film (for example, Regent's Park Open Air Theatre in London). There were, however, several outdoor cinema companies who perceived the anniversary as an opportunity to extend their offer into the realm of ‘augmented cinema'. If not quite matching the scope of the Alamo Drafthouse's efforts, companies such as The Luna Cinema and Motely Movies worked with venues across the UK 
to screen Jaws in a range of outdoor settings that feature water. These included London's Brockwell Lido, Bournemouth’s Pier Approach and Cardiff Bay’s waterfront. The two seaside screenings that serve as our case studies were not dissimilar, both in terms of setting and in terms of being designed and delivered as special one-off events.

\section{[insert fig 1 here. Caption: Inflatable pop-up screen on Hastings Pier open plan deck]}

The impermanence of the Clevedon and Hastings pier screenings as regards time (each screening is for one night only) and space (the pier deck is used for other purposes) suggests a fit with the term 'pop-up', used increasingly across a wide range of contexts and discourses including pop-up shops, restaurants, nightclubs, art exhibitions as well as cinema. As Cultural Geographer Ella Harris notes, 'pop-up is an arena in which space-time is being reimagined in ways that are increasingly influential' (2015: 592). Pop-up can be described as a form of 'insurgent place making' (Merker 2010 cited in Harris 2015: 593) constructed in a contemporary neoliberal context through discourses of flexibility (Harris 2015), immersion (Lashua 2013) and urban redevelopment of 'residual spaces’ (Villagomez 2010 cited in Harris 2015: 596) or 'zombie places' (Lashua 2015). The concept of pop-up has several interesting and creative aspects, such as the way it allows for a playful re-imagining and sometimes radical re-purposing of a space (albeit a temporary one), but also how its temporariness often brings a new energy to a place. Donna de Ville (2013) emphasises site specificity as a primary characteristic of pop-up cinema, suggesting that an entanglement of the activity of spectatorship and the exhibition space lies at the heart of this mode of film consumption. In terms of cinematic culture, more specifically, the term 'microcinema' (de Ville 2015) has been coined to describe 'communal nontheatrical practices' that de Ville argues 'not only offer alternatives to standardized, impersonal megaplex viewing but also 
attempt to introduce sociability into increasingly pervasive individualized moving-image reception in much the same way that book clubs work to give the solitary practice of reading a social dimension' (de Ville 2015: 105). This resonates with the sociability impetus of the community piers and captures the motivation for the deck top pop-up cinema events discussed in our case studies. Furthermore, the pop-up mode of exhibition has several characteristics in common with microcinema, not least the Do-It-Yourself (DIY) 'can do’ ethos and the appetite for unusual spaces and places for cinema. However they stem from different motivations; microcinema came about as a post art house cinema alternative to mainstream viewing venues and retains a specialised cinema profile, whilst pop-up cinema is more about the social or communal activity of enjoying a film in a familiar space that resultantly is thought about and appreciated in a new way. It is not driven by the cineaste's desire for consuming avant-garde or rare films in a quirky location, rather it is rooted in popular culture entertainment, both in terms of content and the deliberate appeal to a wide audience. Thus different in both ambience and content, the pop-up cinema mode of exhibition signifies a different value system whilst operating according to several of the principles of microcinema.

As mentioned earlier, technological developments within the area of digitalised projection $^{3}$, which have made the equipment more mobile and the cost less prohibitive, can be identified as facilitating factors behind the surge of independent companies offering cinema experiences in alternative spaces. The lowering of these barriers affords more freedom in the choice of venue and arguably enables pop-up cinema in unconventional and imaginative spaces. It should be noted though that pop-up strategies have attracted criticism; particularly as concerns how they both express and to an extent reinforce economies of

3 Here we mean the affordances of various kinds of digital projection, as opposed to the more specific understanding of ‘digital projection’ as a Digital Cinema Package (DCP) system. 
precarity and the mechanisms of marginalisation associated with heavy-handed gentrification operating as a 'mechanism through which to mobilize the turbulence of recession and austerity towards a new normal characterised by profitable flexibility and a related precarity’ (Harris 2015: 596). The pop-up phenomenon has also been linked to austerity policies where it operates as a strategy to fill loss-making sites in a flexible way that is both low cost and low risk (Harris 2015).

That said, as Amanda Randall notes, it was the drop in cost for $16 \mathrm{~mm}$ technology and the fact that cinema exhibition equipment became more portable that enabled the development of community cinema in the post-war period (2016: 44). This enabled community groups to utilise mixed-use or occasionally available venues, for film screenings. For both local communities and communities of interest, Randall (216: 45) points out, this repurposing of venues is a key factor for a more social and interest driven approach to film viewing, but also presents a significant challenge as the organisers are often faced with having to overcome difficulties associated with operating in a non-purpose built venue, on a small budget. Nevertheless, she concludes, 'community cinemas prove that in the most unexpected places there is thirst for diverse films that challenge, excite and entertain' (216: 45). With the new pop-up cinema technologies we see this legacy of communities repurposing unconventional venues or locations being developed into new imaginative ventures.

Randall also offers a clue as to why outdoor and enhanced cinema in unusual spaces has become a commercial success; estimating that the equivalent commercial value of community cinema-going, as recorded in a 2014-15 survey through the Cinema for All network, would be in the region of $£ 900,000$. The marketisation of previously DIY community cinema exhibition is not a strand that this chapter will be able to develop further in detail but it is nevertheless relevant to mention here as in the two case study community 
piers the mainstream popular entertainment economy and the community engagement project clearly overlap.

The seaside piers discussed in this chapter are community heritage assets, but they are also heritage attractions that operate in a neoliberal market structure. The flexibility and temporality of the pop-up model is conducive for their needs to stay relevant and interesting to mixed audiences whilst also serving to widen the range of purposes that the open-air space can accommodate. This includes events such as food festivals, speciality markets and fairs, concerts and outdoor cinema but, also, its accommodation of private hire events or its use of the space for family attractions or community events during the day and something more young-adult orientated, like a 'zombie walk' dress-up event, at night. Particularly in the case of Hastings Pier, which is purposefully exploring what a twenty-first century and community orientated pier can be (hastingspier.org.uk/about/hastings-pier-charity/), the opportunity to try out different activities without the costly construction of further permanent purpose-built buildings, is important for the freedom to experiment that the pop-up model offers. So, in this case the pop-up cinema is given a particular context that is different from other venues, as it is slotted in on a regular basis in-between other pop-up features.

Cultural historians and geographers have theorised seaside resorts as 'landscapes of pleasure' (Bull and Hayler 2009: 282) characterised by sites of 'performative play for adults as well as children' (Jarratt and Gammon 2016: 126). However, more recently, the attention has shifted onto 'their economic restructuring and regeneration in response to economic decline' (Bull and Hayler 2009: 282) in costal towns. Both Hastings Pier and Clevedon Pier are implicated in visions for regeneration in their respective localities. The success of the Hastings and Clevedon Piers' community share schemes suggests that local seaside communities do take action that actively contributes to regeneration and the preservation of their heritage assets. However, community participation is a complex and shifting process. A 
venture like a community pier brings with it an array of ambiguous relationships and competing agendas that reflect 'inequalities of resources and power' in the community (Cairns 2003: 112). Researchers critiquing arts-led regeneration strategies have concluded that such strategies are by and large 'congruent with the consumption preferences of the culturally dominant and politically influential’ middle classes (see Griffiths 1993: 41). Some of these tensions are played out in discourse around the restoration and rejuvenation of the two case study piers. Members of the local community resisting the gentrification of the pier, typically express this through a dislike of the modern architecture, concerns over pricing structures - including the premium ticket prices for The Luna Cinema screenings in the case of Hastings Pier - and general concerns about re-purposing the pier (see, for example, comments in the open forum, hastingsforum.co.uk/viewtopic.php?f=6\&t=4065\&p=15164\&hilit=pier\#p15164).

Discourses of taste in entertainment and leisure actives aside, it is clear to us that the affordability of events is a key factor when it comes to community inclusivity and this comes into play in particular when cinema might be used as a means of outreach work among under represented groups such as youth or families.

\section{Testing the water: designing and implementing a methodology}

This study draws on empirical data collected in relation to two case studies, one purposedesigned, and the other participant observation. The authors attended the premier of the documentary Re: A Pier (Lauchlan 2016) on Hastings Pier on 12 May 2016 for the purpose of conducting participant observation. Building on this and encouraged by the popularity of events such as the augmented screenings of Jaws, discussed above, the research team resolved to include a pop-up cinema event on Clevedon Pier as part of their immersive pier 
activities despite the anticipated logistical difficulties. Thus we subsequently designed a popup cinema event together with Clevedon Pier and Heritage Trust staff and volunteers; an outdoor screening of the family adventure film Pirates of Caribbean: The Curse of the Black Pearl (Verbinski 2003) that took place on the pier, on 17 September 2016. On both these occasions the authors collected data through participant observation and correspondence with the community partners. In addition data was collected via survey and interviews during the Clevedon Pier screening. Observations made at a screening of Jaws at Brockwell Lido in 2015 undoubtedly helped with the event's design, in particular the offer of pre-show entertainment (an a capella group of sea shanty singers), use of film-themed accessories (pirate hats), encouragement of picnics as well as consideration of how and when to conduct data collection.

The exhibition of Pirates of Caribbean on Clevedon Pier was designed as a pilot for outdoor cinema on the pier and the audience was invited to partake in the research conducted as part of this pilot. The Re: A Pier screening was not organised around the present research but nevertheless offered a valuable opportunity for participant observation due to the exhibition resonating so strongly with the local audience. In fact Re: A Pier was included in a series of screenings on Hastings Pier run by Kino Digital and The Luna Cinema. It differed significantly from the rest of the summer programme in that it is an independent documentary film as opposed to a popular 'classic' such as Jaws and Dirty Dancing (Ardolino 1987) or a commercially successful British indie film, for example Pride (Warchus 2014). However given that the subject of Re: A Pier is the story of how the people of Hastings saved their pier and the journey of its rebuilding and transformation after the devastating fire in 2010, the documentary by local filmmaker Archie Lauchlan was an ideal title to screen to introduce open-air pop-up cinema onto the pier for the first time. The partly crowd-funded 
documentary had a significant interest for the local audience and the evening was well attended, with an audience size of nearly 350 people.

During the Clevedon Pier event a questionnaire was distributed to the audience at the screening of Pirates of Caribbean. Twenty eight respondents aged 16 and over completed the questionnaire (out of a total number of seventy three visitors). Seventy five per cent of respondents were from the Clevedon area. The questionnaire focussed on two areas of enquiry: the cinema experience and the conception of the pier as a community space. It contained both structured and open-ended questions. A set of twenty six very short exit interviews was also conducted. Consideration was given to the timing of the data collection so not to unduly alter or interrupt the cinema experience and time spent on the questionnaires was kept to the beginning of the programme (while the sea shanty singers performed topical songs to welcome the audience) and the interviews were conducted at the end. Audience members were invited to partake in the research on a voluntary basis, but equally could just come to watch the film.

The two case studies differ in that one was part of a commercial programme by a leading brand in the UK's open-air cinema events market and the other was more in line with DIY community cinema events, organised by the pier's staff and volunteers in collaboration with the research team and the Clevedon Curzon Community Cinema. The screen, digital projector and sound equipment for the latter event were hired from a local media event company. The positioning of the screen on Clevedon Pier was on the pier-head facing the shore-end whilst on Hastings Pier the screen was set up just inside the pier entrance facing the sea. The hands-on involvement in the organisation of the Clevedon event provided us with a valuable understanding of the site as a venue from behind the scenes so to speak, noting challenges such as its vulnerability to the elements (light, wind, rain, the tide) as well as its immersive potential via the layered creation of the pier-head as a cinematic space where 
the seascape and screen blended and the film sound-track played against a backdrop of the shoreline soundscape.

\section{Aesthetic pleasures: the pier-cinema relationship}

As mentioned above, piers were originally built to serve as landing stages but strolling over water soon became a pleasurable pastime. Seaside tourists enjoyed defying the physical impossibility of 'walking on water', marvelling at views inaccessible from shoreline vantage points and, in line with coastal resorts' earlier therapeutic discourse, reaping the health benefits of (the perceived) greater exposure to invigorating sea air. In response to this shift in purpose, the architecture of piers quickly adapted to incorporate dedicated walkways and, later, introduced small-scale artificial attractions that mostly pertained to further consumption of the immediate landscape. As well as benches and 'floating baths', these attractions often included viewing apparatus at the pier-head, such as a telescope or camera obscura (for more detail, see Gray 2006: 201-43). The popularity of these protofilmic devices, combined with the early piers' more basic offer that promenading gives rise to unparalleled panoramas, suggests a connection with cinema that pre-dates the arrival of the pleasure pier proper in the Victorian era and its subsequent twenty-first century use as a pop-up cinema venue.

For further consideration of a relationship between piers and cinema, that draws on a shared spatiovisual bond, it is useful to consult Guiliana Bruno’s innovative work on cinema as 'born of a topographical "sense”' and a practice that has 'established its own sentient way of picturing space' (2002: 8). Her discussion on the genealogy of cinema takes into account the new forms of architecture and aesthetic design that emerged in the mid-nineteenth century and paved the way for a modern construction of space in which bodily motion is key. Bruno singles out the English picturesque (as elaborated by William Gilpin amongst others) as a 
particular significant step in this development; one that anticipated the invention of the moving image. She states: 'As an essential moment in the formation of travelling space, the picturesque revolution took part in the modern making of haptic space and, in so doing, prepared the ground for elements of travelling space in film’ (2002: 192). However, her consideration of picturesque spaces, including the picturesque garden as 'an object of mediated views, where views were a desirable objective’ (2002: 193) also holds true for piers, especially in the earliest phase of their pleasure-giving ventures when the simple act of walking offered the joys of unfolding vistas; a form of visual storytelling. As Fred Gray asserts: 'there were new panoramas of the coast to view, storms and sunsets to marvel at, and horizons to contemplate' (2006: 201). Following Bruno’s line of inquiry then, at its inception the 'promenade pier', like the picturesque garden, was 'a product of imaging and sequentially assembled' and 'thus deployed for viewing as an actual spatiovisual apparatus' (Bruno 2002: 193). It is through this lens that the pier's structure and function can be seen to anticipate the very mechanisms of cinema.

While the UK's surviving piers have responded to the declining popularity of the coastal resort by offering increasingly complex elements of entertainment, the fundamental space-viewing activity that this type of seaside architecture facilitates can still appeal. This is especially true of Clevedon Pier, which remains an uncluttered promenade structure with only a small pavilion (serving as a refreshment room) at the pier-head to divert attention away from the seaside panoramas. In the questionnaire responses, this pier's spatiovisual pleasures are laid out explicitly. Out of twenty eight respondents, eight answered the question 'why do you normally come to the pier' by focusing on the remarkable views obtained from promenading, with a further five suggesting that the privileged perspective of the surrounding coastline plays some part in their decision to frequent the structure. Although clear and succinct phrases - 'to admire the view', 'to enjoy the view', 'for the view' - dominate these 
answers, two respondents offered a little more detail about the scenes and sites that can be enjoyed specifically from a pier vantage point. It is in these answers that further indication of how pier architecture relates to the architectronics of cinema can be found.

In the first of these answers, the respondent highlights the unusual angles that the pier offers the shoreline by singling out Clevedon beach as a particularly interesting view. Naming a site that is clearly visible from the shore suggests that walking the pier and looking back towards land encourages visitors to contemplate the customary perception of the coast's spatial relations and to move into spaces (thus adopt perspectives) traditionally inaccessible. This practice can be likened to certain film techniques that disrupt the consistency of an audience's perspective, such as breaking the 180-degree rule. In contrast, the other respondent's answer suggests that the pier's spatiovisual pleasures are more apparent when maintaining the traditional perspectival gaze that looks out to sea. In this answer, the pier's west-facing position comes into focus as the respondent considers how the structure offers a particularly good spot from which to watch sunsets. Beyond the pier's position on the English coast, however, it is the structure's design that ensures particularly attractive views by guiding visitors towards a complex composition whereby they look down the pier groin, past the pier-head pavilion, and beyond the sea water until their gaze finally meets the sun setting on the distant horizon. The resultant aesthetic effect, in which several distinctive planes are incorporated, suggests the later wide-angles and deep focus techniques seen in cinema.

In the pop-up cinema event at Clevedon Pier the dynamic natural vistas proved a crucial element in the evening's entertainment. With the screening area consciously made accessible from 6:00pm, many audience members were seated in time to watch a spectacular mid September sunset - clear blue skies giving way to bright yellows and warm pinks before the end of nautical twilight signalled the film’s start (8:45pm). It is thus unsurprising that many respondents to the questionnaire make reference to the 'excellent sunset' or 
'stunning surroundings' when asked what aspects of the screening they had most enjoyed. These answers, however, do prompt consideration of past and present practices regarding the traditional window of time that occurs between entering a cinema and the beginning of a feature-length film. Whereas early twentieth century audiences typically admired the spectacular interiors of their picture palaces and enjoyed various forms of live entertainment and vaudeville as well as short films before the main feature, current audiences are more likely to be situated in a featureless multiplex and bombarded by lengthy advertisements that serve to promote the exhibition space primarily as a venue for commercial enterprise rather than as a space for viewing pleasures. With this unwelcome challenge to one of the fundamental pleasures of cinema, is it any wonder that venues that maintain focus on spectacular enjoyment are proving so successful, or that alternative exhibition sites that use ‘stunning surroundings’ are becoming so popular? The aforementioned Alamo Drafthouse theatres in the US and The Luna Cinema screenings in the UK are key examples. The Alamo Drafthouse’s appeal is born from a 'simple passion for watching movies' (drafthouse.com/about/history) that includes an unflinching resistance to advertisements: 'we're vigilant about never letting ads hit our screens [...] we don't want ANYTHING to disrupt your experience of the show' (drafthouse.com/about). Instead, they opt to create custom 'preshows' themed to the features they programme. By comparison The Luna Cinema has found remarkable success with their 'formula' of a 'classic film on a big screen in a beautiful or prestigious setting' (www.thelunacinema.com/about/4560279330). ${ }^{4}$ Despite the screening of Lauchlan's film not strictly adhering to this 'formula', the distinctive structure of Hastings Pier combined with the natural scenery clearly played a significant role in the framing of the consumption of the film and marketing the documentary to the audience The Luna Cinema emphasised both the popular appeal of the documentary 'Re: A Pier tells the

\footnotetext{
${ }^{4}$ The Luna Cinema’s 2015 and 2016 summer programmes both contained over 100 outdoor screenings.
} 
rock and roll story of \#HastingsPier'(Twitter, 9 May 2016) as well as the location and surrounding scenery: 'a very special screening all about the restoration of this iconic landmark, on our huge screen, with the pier and the sea at sunset as an unforgettable background!' (The Luna Cinema Facebook event page, https://www.facebook.com/events/1541161999520772). As with the outdoor screening on Clevedon Pier, viewing pleasures arose from the beside-the-screen spectacle as much as the on-the-screen spectacle, helping to secure 'brilliant cinematic experiences' (www.thelunacinema.com/about/4560279330) as detailed below.

\section{Immersive and social pleasures: popular pop-up cinema and the community pier}

The essential spectacular element of cinema, however, does not account for the entire cinematic experience. As Richard Maltby (amongst others) has pointed out, 'for most audiences for most of the history of cinema' the relationship with 'the cinema' has been founded upon the 'social experience of cinema-going' (2007: n.p.). For the respondents to the Clevedon Pier questionnaire, this certainly holds true. Beyond the scenic views, audiences members cite the social nature of the event - 'everyone together', 'great company', 'night with wife' - as another pleasurable element of the evening. Although these comments could pertain to any collective viewing experience, once placed in dialogue with others that emphasise the pier as a community hub (for example, '[I came] to support the pier and local events'), they suggest that the social lived experience of cinema is more cohesive in smaller, regional locales. The sizeable ticket sales for Re: A Pier on Hastings Pier and the frequent cheers and claps Lauchlan's film received while it screened support this claim. In doing so, these seaside pop-up cinema events resonate with work by Karina Aveyard (2014) on rural cinema-going, taken forward in this volume by Emma Pett, that considers collective action 
and interaction as distinctive markers of cinema attendance outside the big city.

Importantly, the meaningful interpersonal encounters encouraged by the outdoor screenings at Clevedon and Hastings feed into the current rejuvenation of Britain’s coastal resorts, allowing a tradition of pleasurable social exchange to re-emerge. As Rob Shields asserts: 'The chief importance of the seaside resorts had always been social' (1991: 81). Indeed, Shields notes the suspect promotion of the seaside for 'medicinal' purposes during the nineteenth century, suggesting that it was little more than 'a justification for pleasures [...] controlled through a complex set of regulating social rituals' (79). Contemporary understandings of seaside resorts as spaces of leisure, however, did not truly take shape until the late 1800s and early 1900s with the growth of mass tourism, helped by newly opened rail lines, and a subsequent upsurge in artificial attractions. Chief amongst the 'peculiar menu of seaside entertainments' (Walton 2000: 94) now on offer at the British seaside was the pleasure pier.

In this new era of pier design and development, the early promenade structure that had offered its visitors a wealth of spatiovisual delights usually remained in some form but a completely open-deck appearance was fast becoming a rarity; numerous covered buildings (pavilions and theatres) increasingly appeared on the wooden slats, allowing for indoor entertainments that protect the pier’s revenue from the temperamental British weather. Walton offers a detailed description of the pier in its twentieth century incarnation:

\footnotetext{
There was the pleasure pier, as promenading area and a place of assignation, with its distinctive architecture of eclectic frivolity and its musical, comic and dramatic entertainments, from the unpretentious band for open-air dancing and the small 'end-of-pier' show or 'concert party' comprising comic and sentimental songs and sketches, to the substantial orchestra with real (if intermittent) pretensions to 'high culture' (2000: 94).
} 
At Clevedon the pier's delicate design refused to accommodate many of the structural additions required for the more ambitious entertainments but a small, makeshift 'Nissen hut' appeared at the pier-head around 1913, presumably first used as a waiting room for those taking pleasure trips on the sea but certainly facilitating indoor pleasures by the 1930s (see the TV documentary Tis Clevedon Pier). Used as a dance hall, the hut on the pier had enormous cultural and social value for the local population, especially those too young to venture into local pubs or drive to more exciting attractions in Bristol. As the visitors first waltzed and, then, in the post-war era jived the night away, romances were initiated, friendships were strengthened and, in line with the vagaries of the country's youth population, cultural battle-lines were drawn. In the 1950s, for example, Teddy Boys from nearby Weston-super-Mare often spent the early part of their night out lingering at end of Clevedon Pier, disrupting their teenage neighbours’ evening activities (Brennan et al. 2016).

The pop-up cinema event at Clevedon thus served, in part, to re-establish the pier's popular cultural heritage. Having been somewhat side-lined in the redevelopment of the pier over the years, acknowledging and rekindling a vibrant past of youthful entertainments fits with the recent re-purposing of the pier as a community space (emphasised by its community share offer) and, in particular, the desire to have the local population 'see their pier differently’ (Edbrooke 2016: n.p.). Responses in the questionnaires evidence the event's success on this point: when prompted to sum up their experience of the event answers such as 'unexpected', 'lively', 'fun', 'great idea' and 'I wished you’d thought of this sooner' dominated. In this way, it tallies with Brett Lashua's (2013) discussion on pop-up cinema at Marshall's Mill, a protected heritage site in Leeds, northern England, as well as Linda Levitt's consideration of certain sites that host outdoor screenings in Los Angeles, discussed in the following chapter. In these instances, one-off film screenings can be understood to simultaneously recover lost layers of meaning and prompt new contemporary ideas about the 
sites used for exhibition, especially in terms of their capacity to facilitate youthful entertainments. Admittedly at the Clevedon Pier event there were few teenagers in the audience (although there were several pre-teens present) but it remains significant that the largest proportion of the responses to the questionnaire come from 25-34 age range, offering a welcome expansion to the pier's traditional demographic of visitors aged 40 and above (71 per cent $)^{5}$ and suggesting the value of cinema-going to place-making in the twenty-first century.

\section{[insert fig 2 here. Caption: Audience waiting for the sun to set at Clevedon Pier screening of Pirates of the Caribbean]}

The appropriateness of the screening to the pier's popular cultural heritage and, concurrently, its appeal to younger visitors was clearly further strengthened by the film selection. With an age rating of ' 12 ' in the UK Pirates of the Caribbean was a familyfriendly choice but, more significantly, its sea-themed content positioned the pop-up event in a long lineage of pleasure pier spectacles and performances that make use of their distinctive seaside settings, from the once popular acrobatic efforts of humans diving off pier-heads to the aquaria that still mark several of the country’s pier entrances, for example, the Oceanarium in Bournemouth. As with these earlier or more established attractions, the film's sea-themed content worked with its setting to enliven the audience experience, offering in this instance a level of ‘immersion’ (Griffiths 2013: 3) impossible to achieve in a traditional screening space. This 'bodily participation in the experience' (ibid.) was not only aided by the sea views that extended well beyond the frame, filling the audience's peripheral vision in a way that can only be achieved in a covered auditorium via IMAX technology, but also by

\footnotetext{
${ }^{5}$ See Clevedon Pier and Heritage Trust Business Plan 2016-21. Available at: https://www.ethex.org.uk/medialibrary/2015/08/13/90c36657/Business\%20Plan\%20-\%20Final\%20\%20Launch\%2015.pdf
} 
the sounds, smells and tactile sensations offered by the natural surrounds. Several respondents commented on how they thought the 'pirate atmosphere' was a key to their enjoyment of the evening, and although only three respondents indicated they would not watch Pirates of the Caribbean in the cinema this still gives an indication about the perceived added meaning or value the site brought to the experience. One questionnaire respondent, for example, favourably noted how 'smelling the sea' added to the evening's pleasures while a staff member from the Clevedon Curzon Community Cinema remarked: 'It was great fun, with high tide happening below us and the waves rocking the pier slightly!' (Wade 2013: n.p.).

At the Hastings Pier screening the immersive qualities were heightened by $R e: A$ Pier's content, which revealed an indelible connection to the location via the mirroring of the on-screen landscape and Hastings town as its backdrop, the sea soundscape blending with the film sound-track and the situating of the audience on the pier deck where much of the film's narrative unfolds. The augmented cinematic experience was cued by the seemingly spontaneous arrival of the local Section 5 drummers, featured in the film, prior to the screening commencing. This created an atmosphere and level of engagement that gestured towards 'participatory cinema' events (Atkinson and Kennedy 2016a: 142) such as Londonbased Secret Cinema, which combine film screenings with interactive performances in venues that echo the film's setting. In the film the extravagantly dressed band is featured to illustrate the town's community spirit and endearingly idiosyncratic penchant for spectacular forms of street entertainment, so when they entered onto the pier in front of the inflatable screen in May 2016 the event of screening the film in itself was integrated into the continuum of such public displays of local community celebration. 


\section{[insert fig 3 here. Caption: The Luna Cinema, Kino Digital \& Hastings Pier premier screening of Re: A Pier]}

The town's sea front promenade and historical houses as a backdrop to the film created an immersive feeling of being 'in the film' landscape, as did the sound of the waves and the nightlife - youth larking about on the beach punctuated by the sound of an emergency vehicle rushing by in the background. This immersive impression was further underpinned by the wind catching the screen and the ripple animating in ' $3 \mathrm{D}$ ' the waves crashing on the shore as shot on film. On the one hand this created the subtle effect of the film's diegetic world bleeding into the exhibition environment, and on the other hand it offered a historicising continuum as the documentary concentrated on people's memories of growing up on the pier and being immersed in its vibrant youth culture stretching back half a century. The fact that the exhibition arrangement was not designed specifically with this experience in mind did not take away from its impact.

Deliberately designed immersive cinema events, Atkinson and Kennedy point out, work to produce increasingly elaborate surroundings to offer 'compelling, navigable and immersive extensions of the film's fictional environment' (2016b: 257) that have the effect of blending the exhibition environment and the film scenography. Whilst the Re: A Pier screening offered a more serendipitous and inconsistent blend of the film's diegesis and the viewing experience, it nevertheless achieved the effect of bringing the film " "off the screen"' (ibid.).

In the case of the Clevedon screening, several respondents saw the pop-up cinema as breaking new ground in terms of what the space might mean to them. This came through in how they tolerated with good humour some technical problems at the beginning of the evening and in questionnaire responses and exit interviews that both indicate they 
experienced the event as 'unique' and as the beginning of something new and positive: 'please do more, my family will come'. In their responses to what the notion of a 'community pier’ means to them, respondents emphasise three themes in particular: inclusivity, community cohesion and taking ownership: 'a place for the community to come together and enjoy', 'run by and for the community', ‘for the whole community to enjoy and cherish' and 'bring[s] the community together'. Noting the enthusiasm with which the older generation volunteers embraced the tasks of 'setting the scene' for the evening and stewarding throughout the event, dressed in pirate outfits, opportunities for cross-generational exchange were plenty in evidence. To build on this young people could become more involved in the cinema programming and organising of future events.

\section{Conclusion}

This chapter has probed the potential for open-air cinema as a means to engage local audiences to enjoy their pier as a community space, tapping into the site’s history of spatiovisual pleasures whilst also making productive use of its more youth-orientated (audiovisual) popular cultural heritage. We argue that the pop-up cinema is conducive to the architecture of the open plan piers and fits the more events-orientated operational model adopted by pier organisations aspiring to set new goals for the functions of traditional Victorian seaside piers in the twenty-first century. However, whether open-air pop-up cinema on piers is sustainable and can offer significant value in relation to the more long-term project of seaside regeneration is open to questioning. A number of factors, such as their dependency on suitable weather, the varying standard in terms of vision and sound quality, and the economic uncertainty associated with securing revenue from one-off events suggests a limited value and legacy. Nevertheless, innovative and quirky cinema events in unusual 
spaces clearly do have a place in contemporary seaside culture and, as this chapter concludes, open-air cinema is increasingly accessible to community organisations due to new technologies for projection and models of affordability. We posit that open-air cinema enthusiasts will continue to explore exhibition spaces in creative ways that stimulate not just new experiences of films, but new experiences of the exhibition space as impacted by cinematic 'insurgent place making' (Merker 2010 cited in Harris 2015: 593). With this in mind, any further redevelopments of British pleasure piers should be wary of building too many sealed structures that deny these enthusiasts the aesthetic, immersive and social pleasures of being outside.

Further, pop-up cinema has proved to be conducive with the economic model of the community pier in the twenty-first century, which requires flexibility and adaptability. It also fits with an approach that seeks to strike a balance between commercial and cultural-led strategies, as demonstrated by Clevedon Pier and Heritage Trust’s preference for a mainstream film for their pier's screening whilst embracing the DIY set up. Re-purposing a pier for film screenings in the context of the community pier model inevitably involves a consideration of a multitude of complex issues, including questions around programming, audiences’ appropriation of the space, and opportunities for collaborations with other business or community organisations. This complexity should not, however, dissuade the custodians of community piers from designing and delivering outdoor screenings. As this chapter has explored, such special events renew enthusiasm for these Victorian structures, tap into a latent pier-cinema relationship and fuel the UK's developing live cinema culture.

\section{References}

Alamo Drafthouse https://drafthouse.com/about (accessed 20 September 2016). 
Alamo Drafthouse History https://drafthouse.com/about/history (accessed 20 September 2016).

Alamo Drafthouse Rolling Roadshow https://drafthouse.com/series/rollingroadshow (accessed 20 September 2016).

Allen, S. (2008), 'British Cinema at the Seaside: The Limits of Liminality’, Journal of British Cinema and Television, 5 (1): 53-71.

Arthur, S. (2009), 'Blackpool Goes All-Talkie: Cinema and Society at the Seaside in Thirties Britain’, Historical Journal of Film, Radio and Television, 29 (1): 27-39.

Atkinson, S. and H. W. Kennedy (2016a), 'Inside-The-Scenes: The Rise of Experiential Cinema', Participations, 13 (1): 139-51.

Atkinson, S. and H. W. Kennedy (2016b), 'From Conflict to Revolution: The Secret Aesthetic, Narrative Spatialisation and Audience Experience in Immersive Cinema Design', Participations, 13 (1): 252-79.

Aveyard, K. (2015), Lure of the Big Screen: Cinema in Rural Australia and the United Kingdom, Bristol: Intellect.

Brennan, M., L. Brydon, O. Jenzen, A. Lauchlan and N. Nourse (2016), ‘The People’s Pier: 
Popular Culture, Heritage, and Contested Community Spaces’, Conference paper, Changing the Research Landscape Connected Communities Conference, University of East Anglia, UK.

Bruno, G. (2002), Atlas of Emotion: Journeys in Art, Architecture, and Film, New York: Verso.

Bull, C. and S. Hayler (2009), 'The Changing Role of Live Entertainment at English seaside Resorts at the Beginning of the Twenty-First Century', Tourism Geographies, 11 (3): 281-307.

Cairns, T. M. (2003), 'Citizenship and Regeneration: Participation or Incorporation?’, in P. Coare and R. Johnston (eds), Adult Learning, Citizenship and Community Voices: Exploring Community Based Practice, 108-23, Leicester: National Institute of Adult Continuing Education.

Chapman, A. (2015), 'Pier Pressure: Best Practice in the Rehabilitation of British Seaside Piers', Conference paper, REHAB 2015: Proceedings of the 2nd International Conference on Preservation, Maintenance and Rehabilitation of Historical Buildings and Structures, Green Lines Institute, Portugal.

Cripps, K. (2014), ‘Could There Possibly be Any Scarier Way to Watch Jaws?’, CNN, 7 July. Available online: http://edition.cnn.com/2015/07/07/travel/jaws-on-the-water/ (accessed 20 September 2016). 
de Ville, D. (2013), ‘To Pop-up and Back: A Micro-history of Aurora Picture Show’, Incite: Journal of Experimental Media 4: 110-12.

de Ville, D. (2015), 'The Persistent Transience of Microcinema (in the United States and Canada)', Film History, 27 (3): 104-36.

Early Cinema in Scotland, 1896-1927 http://earlycinema.gla.ac.uk/about/ (accessed 20 January 2017).

Edbrook, A. (2016), Email correspondence between Clevedon Pier Heritage and Outreach Officer and the authors.

Feigel, L. (2009), ‘Kiss Me Quick: The Aesthetics of Excess in 1930s Literature and Film’, in L. Feigel and A. Harris (eds), Modernism-On-Sea: Art and Culture at the British Seaside, 15-34, Oxford: Peter Lang.

Fischer, R. and J. K. Walton (1987), British Piers, London: Thames and Hudson.

Gray, F. (2006), Designing the Seaside, London: Reaktion.

Griffiths, A. (2008), Shivers Down Your Spine: Cinema, Museums, and the Immersive View, New York: Columbia University Press.

Griffiths, R. (1993), ‘The Politics of Cultural Policy in Urban Regeneration Strategies’, 
Policy and Politics, 21 (1): 39-46.

Hammond, B. and S. Redmond (2013), 'This is the Sea: Cinema at the Shoreline', Continuum, 27 (5): 601-2.

Handyside, F. (2014), Cinema at the Shore: The Beach in French Film, Oxford: Peter Lang.

Harris, E. (2015), 'Navigating Pop-Up Geographies: Urban Space-Times of Flexibility, Interstitiality and Immersion’, Geography Compass, 9 (11): 592-603.

Hastings Forum

http://hastingsforum.co.uk/viewtopic.php?f=6\&t=4065\&p=15164\&hilit=pier\#p 15164 (accessed 20 January 2017)

Hastings Pier Charity http://hastingspier.org.uk/about/hastings-pier-charity (accessed 15 January 2017).

HoMER Network http://homernetwork.org/about/ (accessed 20 January 2017).

Hooten, C. (2014), 'This is Surely the Best Way to Watch Jaws', The Independent, 3 July. Available online:

http://www.independent.co.uk/arts-entertainment/films/news/this-is-surely-the-bestway-to-watch-jaws-10363456.html (accessed 20 September 2016).

Jarratt, D. and S. Gammon (2016), “"We had the Most Wonderful Times”: Seaside Nostalgia at a British Resort', Tourism Recreation Research, 41 (2): 123-33. 
Lashua, B. D. (2013), 'Pop-Up Cinema and Place-Shaping: Urban Cultural Heritage at Marshall's Mill', Journal of Policy Research in Tourism, Leisure and Events, 5 (2): 123-38.

Lashua, B. D. (2016), 'Zombie Places? Pop Up Leisure and Re-Animated Urban Landscapes’, in S. Gammon and S. Elkington (eds), Landscapes of Leisure: Space, Place and Identities, 55-70, Basingstoke: Palgrave Macmillan.

Maltby, R. (2007), ‘How Can Cinema History Matter More?’, Screening the Past, 22 Available online: http://www.screeningthepast.com/2015/01/how-can-cinema-history-matter-more/ (accessed 20 Sept 2016)

Pirates of the Caribbean: The Curse of the Black Pearl (2003), [Film] Dir. Gore Verbinski, USA: Walt Disney Pictures, Jerry Bruckheimer Films.

Pomerance, M. (2013), 'Young Body on the Beach’, Continuum, 27 (5): 617-29.

Randall, A. (2016), 'Keep it in the Community’, Sight and Sound, 26 (8): 44-5.

Re: A Pier (2016), [Film] Dir. Archie Lauchlan, UK.

Shaw, G. and A. Williams, eds (1997), The Rise and Fall of British Coastal Resorts: Cultural and Economic Perspectives, London: Mansell. 
Shields, R., (1991), Places on the Margin: Alternative Geographies of Modernity, London and New York: Routledge.

The Luna Cinema http://www.thelunacinema.com/about/4560279330 (accessed 20 September 2016).

The Luna Cinema, Kino Digital \& Hastings Pier: Re: A Pier Facebook event page. https://www.facebook.com/events/1541161999520772 (accessed 1 February 2017).

The Luna Cinema (2016) 'We’re showing the fantastic documentary Re:A Pier...' [tweet] https://twitter.com/thelunacinema/status/729615230192517120 (accessed 1 February 2017)

Tis Clevedon Pier (1990), [TV documentary] Dir. Susannah Shaw, UK: BBC West.

Vélez-Serna, M. A. (2016), 'Preview Screenings and the Spaces of an Emerging Local Cinema Trade in Scotland, Historical Journal of Film, Radio and Television, 36 (3): 285-304.

Wade, P. (2016), Email correspondence between Curzon Community Cinema Technical Advisor and the authors.

Walton, J. K. (2000), The British Seaside: Holidays and Resorts in the Twentieth Century, Manchester: Manchester University Press. 
